\title{
Economic Growth, Income Distribution and Building a Modern Economic System
}

\author{
ZHA Tingjun ${ }^{1}$ \\ ${ }^{1}$ Guangdong Institute for International Strategies, Guangdong University of Foreign Studies, Guangzhou China
}

\begin{abstract}
This paper first sorts out the existing research results between economic growth and income distribution; further, through macro data from the export-oriented mechanism of labor-intensive products, the capital owner's interest-biased distribution mechanism, urban-rural dual structure and department Interrevenue distribution and other aspects explore the difference in income distribution between factors and its relationship with economic growth. Secondly, this paper analyzes the internal relationship between the income distribution structure and the construction of modern economic system from efficiency mechanism, fair mechanism and coordination mechanism. Finally, combined with the actual situation of China's economic growth, give the policy recommendations of optimizing the income distribution structure are proposed to promote the construction of modern economic system.
\end{abstract}

\section{INTRODUCTION}

A modern economic system is the economic foundation of a modern and powerful country, and building a modern economic system is the main symbol and major strategic choice for the high-quality development of a developing country's economy (Liu Zhibiao, 2018). With the transformation of China's economy from high-speed growth to high-quality development, the main social contradiction has changed from "the contradiction between the people's increasing material and cultural needs and the backward social production" to "the people's increasing needs for a better life and the unbalanced and insufficient development”. Besides, the connotation centered on economic construction has also changed. Higher-quality economic growth methods and higher-efficiency economic growth levels have become important features of the modern economic system. The modern economic system includes seven organic components: an industrial system, a market system, an income distribution system, an urban and rural regional development system, a green development system, a fully open system, and an economic institution. Among them, the distribution system is the result-sharing mechanism and motivation mechanism for the construction of a modern economic system (Liu Zhibiao, 2019). A distribution mechanism takes both efficiency and fairness into account can promote stable and efficient economic development. However, according to China's Gini coefficient since 2003, China's income gap is still large, which directly leads to rising savings rates and declining consumption rates (Wang Xiaolu, 2015). The consequences have become one of the important factors hindering high-quality economic development.

For an economy, the income distribution decision mechanism is essentially a decisive factor affecting the size and structure of social purchasing power (Zhang Jie and Liu Zhibiao, 2008). The improvement of the overall level of income and the reasonable structure of the distribution mechanism provide effective market demand. By expanding the market size of new products, it will stimulate the innovation activities and profitability of enterprises, and further promote sustained economic growth.

\section{EMPIRICAL ANALYSIS OF CHINA'S INCOME DISTRIBUTION STRUCTURE AND ECONOMIC GROWTH PATTERN}

The difference in the income distribution structure determines the sustainable development of the economy through its impact on micro-subjects (Zhang Jie and Liu Zhibiao, 2008). However, discussions on income distribution have focused on the three dimensions for a long time, interpersonal, regional, and urban-rural factors. The differences in income distribution among factors are ignored. Therefore, analyzing the structural differences among the elements of income distribution helps to understand the dynamic correlation and mutual influence mechanism between income distribution and economic growth.

Since the reform and opening up, China's economy has developed rapidly. As a key component of global income and wealth distribution estimates (Sala-I-Martin, 2006; Lakner \& Milanovic, 2013), the measurement of 
China's income distribution gap and its impact on economic growth has gradually aroused the attention of scholars. According to the research of Piketty et al. (2019), China's income inequality has increased significantly, and the inequality of distribution contains problems such as wealth inequality and urban-rural income gap. Besides, overseas assets and their income will also significantly increase the wealth distribution share of the top population (Alstadsæter at al., 2017). Based on this, this section intends to use macro data to explore the differences in income distribution among factors in terms of the export-oriented mechanism of labor-intensive products, the interest-biased distribution mechanism of capital owners, the dual structure of urban and rural areas, and their relationship with economic growth.

\subsection{Export-oriented mechanism for labor- intensive industries}

In the case of labor surplus and capital shortage in the early stage of development, labor-intensive industries took the lead to develop with their advantages of low labor costs and low capital entry barriers. In addition, China has been at the low end of the global value chain for a long time, this continuous strengthening of the export-oriented mechanism of labor-intensive industries, and has provided the impetus for economic development in China over the past 40 years of reform and opening up. The comparative advantage trade theory believes that the labor income share of exporting companies will increase as the export volume of products with comparative advantages increases. However, this theory ignores the actual situation of export policies and export behaviors in the export process. To a large extent, this will determine whether the labor income share can be increased. Due to the negative "wage spillover" effect produced by the entry of foreign capital, as the degree of foreign investment increases, the share of labor compensation in laborintensive industries has shown a downward trend.

\subsection{The distribution mechanism based on interest-biased distribution mechanism of capital owners}

The asymmetry between residents' property income and wage income has also led to a serious lack of driving force for the construction of a modern economic system (Liu Zhibiao, 2019).

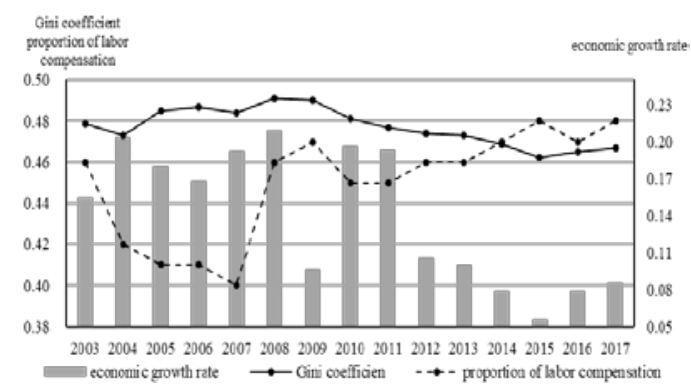

FigurE1 CHINA'S GDP GROWTH RATE, GINI COEFFICIENT, AND PROPORTION OF LABOR COMPENSATION IN GDP
On the one hand, it can be seen from Figure 1 that the proportion of labor compensation and the Gini coefficient show reverse change. From 2004 to 2007, the continuous decline in the proportion of labor compensation, while the Gini coefficient increased significantly. From 2008 to 2017, the proportion of labor compensation continued to rise. The Gini coefficient also shows a downward trend. In general, China's Gini coefficient is still at a relatively high level, income distribution inequality is relatively serious, and the proportion of labor compensation has continued to remain at a low level. In contrast, the average proportion of labor compensation in the United States during the same period reached $54.80 \%$. On the other hand, the Gini coefficient and economic growth show the same trend of change. From 2003 to 2011, the Gini coefficient remained at a relatively high level, with an average value of 0.48 , and the economic growth rate at this stage was also high, with an average value exceeding 17\%. However, from 2012 to 2017, with the gradual decline of the Gini coefficient, the economic growth rate slowed down significantly, with an average value of only $8 \%$.

In the early stage of development, under the conditions of labor surplus and capital shortage, wage levels are generally at a low stage, and the income distribution mechanism is biased towards capital owners, making the Gini coefficient at a higher level, and the inequality of distribution is serious. At this time, economic growth is relying on the development of laborintensive industries for the primitive accumulation of capital, when the economy has developed to a certain stage, as labor costs continue to rise and the marginal return of capital decreases, the inherent development model brings about a slowdown in economic growth. With the gradual increase in the proportion of labor compensation, inequality in distribution has also eased.

\subsection{The dual segmentation of urban and rural areas and the difference in departmental income distribution}

Regional differences and industry differences are important sources of income inequality. Among them, regional differences are mainly manifested in the income differences between residents of different provinces or cities, and between urban and rural areas. The long-term low wages of workers are inseparable from China's "dual" urban-rural division system (Zhang Jie and Liu Zhibiao, 2008). 
TABLE1 CHINA'S LABOR COMPENSATION IN GDP

\begin{tabular}{|l|l|l|l|l|}
\hline & $\begin{array}{c}\text { percentage } \\
\text { of } \\
\text { disposable } \\
\text { income: } \\
\text { corporate } \\
\text { sector }\end{array}$ & $\begin{array}{c}\text { percentage of } \\
\text { disposable } \\
\text { income: } \\
\text { government } \\
\text { sector }\end{array}$ & $\begin{array}{c}\text { percentage } \\
\text { of } \\
\text { disposable } \\
\text { income: } \\
\text { household } \\
\text { sector }\end{array}$ & $\begin{array}{c}\text { economic } \\
\text { growth }\end{array}$ \\
\hline 1992 & 13.40 & 17.90 & 68.70 & 0.22 \\
\hline 1993 & 18.10 & 17.20 & 64.70 & 0.32 \\
\hline 1994 & 18.60 & 14.50 & 66.90 & 0.33 \\
\hline 1995 & 19.70 & 14.10 & 66.20 & 0.27 \\
\hline 1996 & 16.40 & 14.60 & 69.00 & 0.19 \\
\hline 1997 & 17.70 & 14.30 & 68.00 & 0.12 \\
\hline 1998 & 17.50 & 14.20 & 68.30 & 0.08 \\
\hline 1999 & 19.20 & 14.10 & 66.70 & 0.06 \\
\hline 2000 & 19.40 & 14.50 & 66.10 & 0.11 \\
\hline 2001 & 20.60 & 15.00 & 64.40 & 0.12 \\
\hline 2002 & 21.10 & 16.30 & 62.60 & 0.11 \\
\hline 2003 & 21.90 & 16.10 & 62.00 & 0.15 \\
\hline 2004 & 24.30 & 16.60 & 59.10 & 0.20 \\
\hline 2005 & 23.70 & 17.40 & 58.90 & 0.18 \\
\hline 2006 & 23.70 & 17.90 & 58.40 & 0.17 \\
\hline 2007 & 23.90 & 18.80 & 57.30 & 0.19 \\
\hline 2008 & 24.50 & 18.30 & 57.20 & 0.21 \\
\hline 2009 & 23.80 & 17.50 & 58.70 & 0.10 \\
\hline 2010 & 23.60 & 18.00 & 58.40 & 0.20 \\
\hline 2011 & 21.90 & 18.80 & 59.30 & 0.19 \\
\hline 2012 & 20.60 & 19.20 & 60.20 & 0.11 \\
\hline 2013 & 19.80 & 18.90 & 61.30 & 0.10 \\
\hline 2014 & 20.50 & 18.85 & 60.65 & 0.08 \\
\hline 2015 & 19.80 & 18.50 & 61.60 & 0.06 \\
\hline 2016 & 20.00 & 17.90 & 62.10 & 0.08 \\
\hline
\end{tabular}

The growth of per capita disposable income of urban households is much faster than the growth of per capita net income of rural households. It can also be clearly seen from the figure that 1994 was the demarcation point for the formation of the urban-rural dual structure. Before that, the annual average per capita disposable income of urban households was 1,175.62 yuan, and the annual average per capita net income of rural households was 493.86 yuan. The former was 2.38 times of the latter. However, after 1994, the gap gradually widened. The annual average per capita disposable income of households reached 15921.62 yuan, while the annual average per capita net income of rural households was only 5,492.13 yuan. The former was 2.90 times of the latter. The growing scissors gap between urban and rural per capita income has caused regional imbalances in distribution.

In addition, there is a certain correlation between the changes of economic growth and the distribution of disposable income among sectors. It can be seen from Table 2 that since the 1990s, China's national income distribution pattern has undergone major changes. In the distribution pattern of the proportion of disposable income, the proportion of the corporate sector has gone through a process of rising first and then declining. Especially before 2008, the proportion of the corporate sector's disposable income increased rapidly and stabilized, while the government sector showed opposite trend and stabilized after 2008, remaining at about $18 \%$. The household sector's disposable income accounted for the highest proportion. It can be seen from this that the rapid increase of non-system income and land transfer income has significantly increased the share of government income, and has squeezed out the disposable income of corporate and household sectors. Enterprises are obviously in the disadvantaged position of redistribution pattern.

\section{THE INTERNAL RELATIONSHIP BETWEEN THE OPTIMIZATION OF INCOME DISTRIBUTION STRUCTURE AND THE CONSTRUCTION OF A MODERN ECONOMIC SYSTEM}

The internal relationship between the optimization of the income distribution structure and the construction of a modern economic system is concentrated in the fact that the former is the basic requirement and fundamental symbol of the latter (Liu Zhibiao, 2018), which means that the optimization of the income distribution structure not only pursues efficiency incentives in the initial distribution, but also gradually narrow the income distribution gap and advance the equalization of basic public services by using redistribution tools.

\subsection{The efficiency mechanism in the initial distribution}

The primary distribution is the focus of the current reform of China's income distribution system, because it is an important reason for the large income gap in China ( $\mathrm{Li}$ Yining, 2013). According to mainstream market theory, the market mechanism can achieve Pareto optimal resource allocation under the automatic adjustment of the "invisible hand", and the initial allocation is the result of this market mechanism. In China's economic reality, due to various reasons, the market mechanism is not sound and perfect, which also causes serious distortions in the initial distribution process. For example, under the path dependence caused by the long-term implementation of the planned economy in the past, wage extremes are still widespread, and they have affected the initial distribution process. Another example is the export-oriented development model based on labor-intensive industries. Workers can only get meager profits and wages, and most of the income in the initial distribution process is owned by foreign investors. Therefore, our primary distribution need reform, but this reform should be combined with the industrial transformation and upgrading of the real economy in order to truly give play to the efficiency incentives of primary distribution. The reason is that: on the one hand, only when the real economy's industries are 
transformed and upgraded, and get rid of the low-end foundry in the global value chain, can the situation of being "captured" by foreign investors in the initial distribution process be completely changed. On the other hand, the number of innovative entrepreneurs under the influence of transformation and upgrading is increasing, and under the influence of capital bias in modern economic growth, the trend of increasing income distribution gap will inevitably be curbed. Under such circumstances, "When the granary is solid, etiquette is known; when food and clothing are sufficient, honor and disgrace are known" will help increase production enthusiasm, thus further promote industrial innovation and development, and promote the construction of a modern economic system.

\subsection{Fair mechanism in redistribution}

Generally speaking, there are various forms of redistribution, but in the final analysis, they mainly consist of transferring income to low-income earners and taxing high-income earners, but the redistribution policy effect of the former is much higher than the latter (Kristjánsson, 2011). Therefore, the government's transfer of expenditures to residents is an important means to achieve fair income distribution. However, the redistribution mechanism in developing countries is generally lacking. This is because the public finances of developing countries are basically unable to perform the function of adjusting income gap. Take China's social security expenditure as an example. It is a typical transfer expenditure mechanism for residents. However, there is a phenomenon of "overdistribution" to some groups at present, which leads to the extremely low efficiency of the redistribution mechanism of social security expenditure in China (Xu Jing et al., 2018). In fact, from the experience of developed countries, social security expenditures can completely improve the "dual" structure of rural and urban income distribution by increasing policy subsidies for rural residents and reducing policy subsidies for urban residents. However, it needs to be emphasized that since China's public-owned economy occupies the main body, the adjustment of the income redistribution mechanism should take the special factors of the institutional mechanism into account. This means that we must firmly grasp the main line of reforming the relationship between the government and the market and improve the socialist market economic system, so as to promote the equalization of basic public services and achieve common prosperity.

\subsection{Coordination mechanism for initial distribution and redistribution}

Both primary distribution and redistribution are an indispensable and important part of the reform of income distribution system, and their functional positioning mainly revolves around the internal coordination of efficiency and fairness. From the point of view, efficiency and fairness seem to be just a dilemma between the tradeoffs, but in fact, high efficiency does not necessarily mean sacrificing fairness, and sacrificing fairness will damage efficiency (Li Qingbin, 2019). In other words, if the fairness mechanism in redistribution is artificially distorted, it will inevitably deepen the contradictions and conflicts between the different income classes of social residents, and have an adverse effect on the economic production enthusiasm of the entire society. It can be seen that the functional positioning of primary distribution and redistribution are actually complementary to each other. Therefore, coordination between primary distribution and redistribution is an inevitable requirement for a fair, efficient and sustainable income distribution system, and it is also one of the main contents of the construction of a modern economic system.

\section{Policy RECOMmendations}

China is currently in the transitional stage from highspeed growth to high-quality development. The income distribution process not only has the problem of excessive income gap, but also the problem of unfair income distribution. Therefore, this article combines the actual situation and puts forward the following specific policy recommendations:

First, further improve and perfect the market mechanism, strive to eliminate the inequality of the buyer and seller in the labor market, and create a fair competition environment for the demand and supply of production factors. In particular, with regard to some wage standards and extremely poor regulations in the initial distribution process, reforms are urgently needed to effectively penetrate the principle of the market's decisive role in the initial distribution.

Second, encourage the public to innovate and start businesses on their own, and create a good environment for innovation and entrepreneurship. Under the influence of the capital bias of modern economic growth, capital owners can often have an advantage in the income distribution process. Therefore, there will be a good pattern in which the average social wealth is higher than the median when there are more people innovating and starting businesses.

Third, vigorously develop the domestic value chain, and then use the domestic value chain to climb the highend links of the global value chain. The development of domestic industries with high productivity and high added value, such as advanced manufacturing and modern service industries, is not only conducive to cultivating and strengthening China's middle-income class, but to a certain extent can effectively curb the large loss of domestic wealth.

Fourth, strengthen the supply of high-quality systems, especially in the redistribution process. Redistribution mainly relies on the government's power. Therefore, whether the government can provide high-quality institutional supply is particularly important. For example, a policy of enriching the people with lower limits requires high-quality government system functions to support it.

Fifth, pay attention to both the primary distribution function and the redistribution function, and use the synergy between them to optimize the income distribution 
structure of our country. Specifically, the focus of the initial distribution should be on the efficiency incentive mechanism, and the focus of the redistribution should be on the fair mechanism. This requires policy design, especially in the formulation of some specific policies, should consider the national conditions and comprehensive consideration of the possible effects of initial distribution and redistribution.

\section{ACKNOWLEDGEMENT}

This work was supported by Guangzhou Philosophy and Social Sciences Development "13th Five-Year Plan" 2019 Project (2019GZYB45); Guangdong Province Educational Science "13th Five-Year Plan" The 2019 Special Research Project of Philosophy and Social Sciences in Colleges and Universities (2019GXJK091).

\section{REFERENCES}

1. Alstadsæter A, Johannesen N, Zucman G. "Who Owns the Wealth in Tax Havens? Macro Evidence and Implications for Global Inequality,” Journal of Public Economics, 2017, vol. 162, pp. 89-100.

2. Kristjánsson A S. "Income redistribution in Iceland: Development and European comparisons,” European Journal of Social Security, 2011, vol. 4, pp. 392-423.

3. Lakner C, Milanovic B. "Global Income Distribution from the Fall of the Berlin Wall to the Great Recession,” Policy Research Working Paper, 2013, vol. 32, pp. 71-128.

4. Li Qingbin. "Build an income distribution system that reflects efficiency and promotes fairness," Macroeconomic. Management, 2019, vol. 5, pp. 1723.

5. Li Yining. “Comprehensively Deepen Reform and Opening Up and Promote Sustained and Healthy Economic Development," Economic Research Journal, 2013,vol. 3, pp. 4.

6. Liu Zhibiao. "A Study of Modern Economic System Construction: Its Framework, Key Issues and Theoretical Innovation,” Journal of Nanjing University(Philosophy, Humanities and Social Sciences), 2018, vol. 3, pp. 5-12.

7. Liu Zhibiao. "Development Bottlenecks and Policy Priorities in Building the Modern Economic System,” China Economic Studies, 2019, vol. 2, pp. 19-26.

8. Sala-I-Martin X . "The World Distribution of Income: Falling Poverty and Convergence," Quarterly Journal of Economics, 2006, vol. 2, pp. 351-397.

9. Wang Xiaolu. "Economic growth, income distribution and structural adjustment," Reform of Economic System. 2015, vol.1, pp. 14-15.

10. Xu Jing, Cai Meng and Yue Ximing. "The Income Redistribution Effect of Government Transfer
Programs,” Social Sciences in China, 2018, vol.10, pp. 39-58.

11. Zhan Jie, Liu Zhibiao. "Demand and the formation of China's independent innovation ability: Based on the perspective of income distribution," Research on Economics and Management. 2008, vol. 2, pp. 33-37. 